\title{
A Service Yips Experiences in Badminton Players
}

\author{
Jae-Youn Jeon ${ }^{1}$, Hyeon-Ju Kim ${ }^{2 *}$, Jeong-Su Kim ${ }^{3}$, \& Sang-Hyuk Park ${ }^{1}$ \\ ${ }^{1}$ Korea Institute of Sport Science, ${ }^{2}$ Korea National Sport University, \& ${ }^{3}$ Semyung University
}

\begin{abstract}
[Purpose] This study aims to investigate the experience of service yips in badminton players in depth through using grounded theory method. [Methods] We collected data from in-depth interviews with 14 participants in total, consisting of badminton players who experienced service yips, their doubles partners and coaches. The collected raw data were analyzed base on derive transcription, coding and paradigm models through grounded theory method. [Results] First, as a result, 59 concepts, 31 subcategories and 15 categories in regard to badminton service yips were deduced from open coding. Second, in axial coding, it was structured in a paradigm model by categories such as service yips, service mistakes, service proficiency, service anxiety, the imprinting experiences, the importance competition, the pressure of achievement, service practice, psychological control, tactical handling, support from partners, leaders' coaching, advice from experienced ones, overcoming yips and persistent yips. Third, selective coding resulted in 'Badminton service yips' as the core category of this study. 'Badminton service yips' is a chronic performance impairment associated with badminton players making severe errors in swing motion on a service not intended by them that it is due to physiological or psychological symptoms such as hand tremors, overall body stiffness, arms stiffness, overstress, overanxiety, and concern over service mistakes. [Conclusion] We expect our study can be a theoretical foundation for understanding and explanation of 'Badminton service yips' and a useful reference for badminton players suffering from psychological difficulties caused by their service yips. The findings in this study should be considered for the development of potential strategies for overcoming the badminton service yips.
\end{abstract}

Key Words: Service yips, Badminton players, Leader’s Coaching, Overcoming yips, Ground theory method.

\section{서 론 \\ 입스(Yips)는 주로 골프에서 사용하는 용어로 선수들의 수행을 악화시키는 심각한 심리적 부상 또는 심리적 질병으 로 알려져 있다. 입스는 운동수행 시 강한 압박감이나 불안 이 원인이 되어 근육 경직 또는 경련이 일어나는 증상}

논문 투고일 : 2020. 11. 18.

논문 수정일 : 2020. 12. 16.

게재 확정일 : 2021. 01. 19.

* 교신저자 : 김현주(jhjlove11@naver.com).
(Smith et al., 2003)으로써 불수의적 근육 수축으로 인해 계획한 동작의 통제력을 상실하는 신경생리학적 증상 (Bawden \& Maynard, 2001)때문에 수행 관련 국소적 근 긴장증(focal dystonia), 신경병리학적 운동장애, 직업 경 련, 만성적 초킹 등 다양하게 정의되고 있다(Adler, Crews, Hentz, Smith, \& Caviness, 2005; Beilock \& Gray, 2007; Hill, Hanton, Matthews, \& Fleming, 2010; Masters \& Maxwell, 2008; McDaniel, Cummings, \& Shain, 1989; Sachdev, 1992; Smith et al., 2003). 입스는 선수로 하여금 신체적, 심리적 증상을 유발해 최 
악의 수행을 하게 한다. 입스가 발생한 선수는 운동수행 시 순간적인 경련이나 경직, 과도한 근육 긴장, 가슴 통증 및 압 박, 심박수 증가 등과 같은 신체적 증상과 과도한 불안, 집중 력 분산, 수행 공포감, 어지러움 등의 심리적 증상을 경험한 다(Rosted, 2005; Stinear, Coxon, Fleming, Lim, Prapavessis, \& Byblow, 2006). 이러한 신체적, 심리적 증상은 심각한 수준의 실수를 유발하고, 심한 경우 해당 기 술을 사용하지 못해 휴식기를 갖거나 은퇴를 결정하게도 한 다(Marquardt, 2009; Philippen \& Lobinger, 2012; Sachdev, 1992). 따라서 입스는 슬럼프와 같이 대부분의 선수가 겪는 일반적 현상이 아닌 몇몇 선수만이 경험하는 독 특한 심리적 질병이다(Roberts, Rotheram, Maynard, Thomas, \& Woodman, 2013).

스포츠 전반에서 보면 입스는 보편적 심리현상이다 (Bennett, Hays, Lindsay, Olusoga, \& Maynard, 2015). 입스 증상은 골프뿐만 아니라 여러 종목에서 발견되 는데, 예를 들어 야구에서는 스티브블래스증후군(Steve Blass syndrome)으로 불리고 있다. 이외에도 다트와 크리 켓(Bawden \& Maynard, 2001), 양궁, 테니스, 배드민턴 등 다양한 종목에서는 입스와 유사한 형태의 심리적 문제를 호소하지만 이를 이해하고 설명할 수 있는 연구는 다소 부족 한 실정이다.

그동안 체육학계에서는 골프 선수의 입스 경험에 관한 역 학적 조사(Lee, 2006; Smith et al., 2000), 입스 발생 시 심리, 생리, 역학적 변화(Dhungana \& Jankovic, 2013; Kläampfl, Lobinger, \& Raab, 2013a, 2013b; Smith et al., 2003), 입스 현상에 관한 심층적 탐색(Back, 2017; Ko \& Huh, 2016; Park, 2009; Philippen \& Lobinger, 2012; Sim \& Sul, 2016), 입스 극복을 위한 심리적 개입 (Bell \& Thompson, 2007; Bell, Skinner, \& Fisher, 2009; Han, 2017; Milne \& Morrison, 2015) 등에 관한 연구가 진행되어 왔다. 이들 연구는 입스의 원인과 증상, 수 행에 미치는 영향 등 입스 현상에 대한 심층적 이해를 도모 하고, 심리적 극복 방안을 마련하는데 이론적 토대를 제공 하였다.

특히, 입스 극복 및 대처 방안 탐색 연구(Back, 2017; Baik, 2019; Cho, Yook, Choi, \& Shin, 2015; Choi \& Chai, 2016; Ko \& Huh, 2016)와 입스 극복을 위한 심리 기술훈련 적용 연구(Bell \& Thompson, 2007; Bell et al., 2009; Han, 2017; Milne \& Morrison, 2015)는 입스가
심리개입 및 훈련을 통해 극복 가능하며, 다양한 심리적 시 도와 개입이 입스 극복의 가능성을 증가시킬 수 있음을 입증 하였다. 실제, 입스를 경험한 선수는 휴식과 기술 분석 및 변 화 시도, 반복훈련 뿐만 아니라 심상, 자화, 루틴과 같은 심 리 훈련과 개입을 통해 극복하였다. 따라서 모든 선수가 입 스를 극복하는 것은 아니지만 심리적 개입과 체계적 지원이 입스 극복을 가능하게 함은 분명하다.

그럼에도 대부분의 입스 연구는 골프 종목에 국한되어 다 양한 종목에서 경험하는 입스를 이해하는 데는 한계가 있 다. 입스는 특정 기술을 수행하는 과정에서 발생(Bawden \& Maynard, 2001)하기 때문에 해당 종목은 물론 입스 발 생 기술에 관한 이해와 심층적인 연구 접근이 기반 되어야 한다. 또한 입스는 몇몇 선수만의 독특한 경험이기 때문에 입스 극복을 위한 심리지원 방안 모색을 위해서는 입스 발생 부터 극복까지 종합적 관점에서 연구해야 입스에 대한 전체 적인 현상 파악과 해결 방안 모색이 가능하다(Han, 2017).

한편, 배드민턴은 복잡한 운동기술을 수행하는 종목으로 빠른 랠리 과정에서 정교한 운동기술이 요구되며, 역전이나 듀스 등 심리적으로 민감한 상황이 연출된다(Jeon \& Yun, 2014). 또한 경기 흐름이나 심판 오심, 지도자 벤치코칭 등 다양한 내 - 외적 요인이 선수로 하여금 높은 수준의 불안과 압박감을 경험하게 한다(Jeon, 2014; Kim, Gu, Kim, \& $\mathrm{Kim}, 2011)$. 실제, 국내 · 외 배드민턴 현장에서는 서비스 기술 수행에서 입스를 겪고 있는 선수가 종종 발견된다. 배 드민턴 경기에서 서비스는 여러 기술 중 가장 기본이 되는 기술로 높은 정확도가 요구되며, 득점 및 승리하기 위해서 는 반드시 수행해야 하는 기술이기 때문에 입스가 발생할 경 우 경기력 악화로 이어질 위험성이 높다. 따라서 배드민턴 선수의 서비스 입스 탐색 연구는 선수의 입스 경험에 대한 이해는 물론 입스 극복을 위한 심리지원 방안 모색에 기여할 수 있다.

지금까지 배드민턴 종목에서는 선수의 입스 관련 연구는 찾아보기 힘든 실정이다. 국내 배드민턴 선수를 대상으로 한 스포츠심리학 연구는 성취목표성향이나 내적동기, 자기 효능감, 스트레스, 불안 등과 같은 심리 특성과 경기력의 관 계(Choi, 2011; Choi \& Kim, 2008; Lee \& Huh, 2006; Jang \& Yun, 2003), 타구코스 예측 및 시각탐색 전략 $(\mathrm{Gu}$, Lee, Kim, Kim, \& Han, 2009; Kim, Gu, Park, \& Lee, 2007; Sung \& Gu, 1992), 경기에서의 심리적 경험과 조절 (Lee \& Gu, 2003; Jeon, 2014; Jeon \& Yun, 2014; 
Jeon, Yun, Kim, \& Park, 2019), 경기력 향상을 위한 심 리기술훈련 적용(Gu et al., 2009; Gu, Kim, Sung, Kim, Kim, Kim, Kang, \& Lee, 2012; Han, Kim, \& Jung, 2014; Kim \& Jung, 2014) 등을 주제로 진행되었다.

더불어 배드민턴 선수의 서비스 기술에 관한 연구(Ha, Kim, Gu, \& Park, 2010; Jung, 2007; Kim, 2000; Noh, 2012; Ra, 2002; Yoon \& Lee, 2015)는 단식, 혼/복식 경 기에서 서비스 및 리시브 코스와 종류 등을 분석하는데 초점 을 두고 있다. 이들 연구는 대부분 경기영상 분석을 통해 서 비스 코스와 리시브의 관계를 분석함으로써 우수선수들의 기술적 특징을 파악하고, 득점 확률을 높일 수 있는 전술을 모색하는데 유용한 정보를 제공한다. 이는 배드민턴 경기에 서 정확한 서비스 수행이 중요함을 방증하지만, 서비스 수 행 시 나타나는 선수의 심리적 증상과 구체적인 경험에 관한 정보는 제공해주지 못하고 있다. 따라서 배드민턴 선수의 서비스 수행에서 발생하는 입스를 이해하고 설명할 수 있는 연구가 필요하다.

이상을 종합해 본 연구에서는 배드민턴 선수의 서비스 입 스 경험을 심층적으로 탐색하고자 하였다. 구체적으로 근거 이론방법을 활용하여 배드민턴 서비스 입스 발생부터 극복 하는 과정에서 영향을 미치는 요인을 도출하고 범주화, 구 조화, 체계화하여 배드민턴 서비스 입스를 이해하고 설명할 수 있는 근거이론을 개발하고자 하였다. 향후 본 연구를 통 해 배드민턴 선수의 서비스 입스 예방 및 극복을 위한 심리 지원 방안을 마련할 수 있기를 기대한다.

\section{연구방법}

\section{연구참여자}

본 연구에서는 배드민턴 서비스 입스를 경험한 현역 및 은 퇴선수 6명과 그들의 복식 파트너 4 명, 지도자 4 명 총 14 명 을 면담 대상자로 선정하였다. 본 연구의 참여자는 배드민턴 서비스 입스라는 독특한 심리적 증상을 경험한 선수로서 스 노우볼표집법(snowball sampling)과 세평적 사례 선택방 법(reputational case selection)을 활용하여 선정하였다. 배드민턴 서비스 입스에 관한 간접 경험 정보를 동시에 수집 하기 위해 〈Table 1)과 같이 서비스 입스 경험 당시 해당 선 수의 복식 파트너와 지도자를 면담 대상자로 선정하였다.
Table 1. Characteristics of the participants

\begin{tabular}{|c|c|c|c|c|c|}
\hline \multicolumn{2}{|c|}{ Participant } & Event & Sex & Age & $\begin{array}{l}\text { Player/Coach } \\
\text { Career }\end{array}$ \\
\hline \multirow{6}{*}{ Players } & $\mathrm{A}$ & Singles & $\mathrm{F}$ & 30 & 18 \\
\hline & $\mathrm{B}$ & Mix/Doubles & $\mathrm{M}$ & 32 & 24 \\
\hline & $\mathrm{C}$ & Mix/Doubles & $\mathrm{F}$ & 31 & $19 / 1$ \\
\hline & $\mathrm{D}$ & Doubles & $\mathrm{F}$ & 41 & $21 / 7$ \\
\hline & $E$ & Doubles & $M$ & 46 & $20 / 11$ \\
\hline & $\mathrm{F}$ & $\begin{array}{l}\text { Singles/ } \\
\text { Doubles }\end{array}$ & $\mathrm{F}$ & 39 & $20 / 4$ \\
\hline \multirow{4}{*}{$\begin{array}{c}\text { Doubles } \\
\text { partner }\end{array}$} & $\mathrm{G}$ & Mix & $\mathrm{F}$ & 28 & 19 \\
\hline & $\mathrm{H}$ & Doubles & $\mathrm{F}$ & 32 & 22 \\
\hline & $\mathrm{I}$ & Doubles & M & 46 & $19 / 6$ \\
\hline & $\mathrm{J}$ & Doubles & $\mathrm{F}$ & 40 & $18 / 7$ \\
\hline \multirow{4}{*}{ Coach } & $\mathrm{K}$ & Singles & $\mathrm{M}$ & 50 & $24 / 16$ \\
\hline & $\mathrm{L}$ & Mix/Doubles & $\mathrm{F}$ & 45 & $22 / 13$ \\
\hline & $\mathrm{M}$ & Singles & $\mathrm{M}$ & 41 & $17 / 13$ \\
\hline & $\mathrm{N}$ & Doubles & $M$ & 38 & $24 / 4$ \\
\hline Total(N) & & & 14 & & \\
\hline
\end{tabular}

\section{자료수집}

본 연구에서는 심층면담과 현장관찰을 활용하여 자료를 수집하였다. 먼저 배드민턴 선수의 서비스 입스 경험을 탐 색하기 위하여 $1: 1$ 심층면담을 통해 자료를 수집하였다. 초 기 면담에서는 입스에 관한 문헌고찰과 스포츠심리학 교수 및 배드민턴 지도자의 의견을 수렴하여 비구조화 면담지침 을 제작하였다. 면담 대상을 서비스 입스 경험 선수로 제한 하였기 때문에 초기 면담지침은 참여자가 서비스 입스 발생 당시를 회상하여 자신의 경험을 자유롭게 이야기하도록 하 였다. 이후 면담부터는 면담자료에 대한 내용분석 결과를 토대로 면담지침을 구체화하여 반구조화 면담을 진행하였 다. 예를 들어, 입스 경험 시 원인과 증상, 수행의 변화, 경기 력 및 선수생활에 미친 영향, 극복 방법, 타인의 도움 등 구 체적인 질문을 더해가며 면담지침을 수정, 보완하였다. 면 담 자료에 대한 분석 과정에서 이해가 되지 않거나 더욱 구 체적인 정보가 필요한 경우에는 전화나 추후 면담 일정을 조 율해 반복 면담을 진행하였다.

심층면담은 사전 전화 연락을 통해 연구 목적을 설명하고 일정과 장소를 조율하였다. 2019년 3월부터 6월까지 총 14 명의 대상자를 18 회에 걸쳐 대상자가 원하는 장소(훈련장, 사무실, 커피숍 등)에서 약 60 분 동안 면담하였다. 면담 진 행시에는 면담내용의 비밀보장, 자료 활용 시 익명성 보장, 
녹음 허락, 면담 사례비 등에 대해 설명하고 동의하는 경우 동의서에 서명하도록 하였다. 면담내용은 핸드폰과 녹음기 를 사용해 녹음하고, 녹음한 내용은 이후 전사하였다.

배드민턴 서비스 입스는 몇몇 선수의 독특한 심리 경험이 므로 배드민턴 현장과 입스 현상에 대한 이해가 선행되어야 한다. 따라서 연구자는 3 개 국제대회와 2개 국내대회를 참 관하며 국내 - 외 배드민턴 선수의 수행에서 나타나는 서비 스 입스 현상을 이해하려고 노력하였다. 실제, 국내·외적 으로 서비스 수행에 어려움을 겪고 있는 선수들이 있는데, 해당 선수의 경기를 직접 관전하며 서비스 입스 증상이 드러 나는 맥락과 현상을 파악하고자 하였다. 현장관찰 시에는
목격한 장면과 관찰 시 떠오르는 생각과 느낌, 이후 면담할 질문 등을 메모하고 필요한 경우 핸드폰으로 사진과 영상을 촬영하여 기록하였다. 현장관찰 중에 얻은 정보와 자료는 분석과정에서 참고자료로 활용하였다.

\section{자료분석}

본 연구에서는 Strauss와 Corbin(1998)의 근거이론방 법을 활용하여 자료를 분석하였다. 근거이론은 질적연구방 법에서 체계적으로 수집된 자료를 근거로 이론적 체계, 과 정, 실행 또는 실질적 주제에 관한 상호작용 등을 설명하는

Table 2. Results of open coding

\begin{tabular}{|c|c|c|}
\hline Concepts(59) & Sub-category(31) & Category(15) \\
\hline $\begin{array}{l}\text { Hand tremor, Body and arm stiffness, Increased heart rate, } \\
\text { Feeling of pulling }\end{array}$ & Physiological symptoms & \multirow{3}{*}{ Service yips } \\
\hline $\begin{array}{l}\text { Embarrassment, Increased tension/anxiety, Worry about mistakes, } \\
\text { Fear of service }\end{array}$ & Psychological symptoms & \\
\hline Operation error, Serious mistake & Loss of control & \\
\hline Mistakes in the finals, Mistakes in the Olympics & Mistakes in an important match & \multirow{2}{*}{ Service mistakes } \\
\hline Repeat mistakes & Repeat mistakes & \\
\hline Swing(batting) problem, How to hold the shuttlecock & Inexperienced service & \multirow{2}{*}{ Service proficiency } \\
\hline Consistency of motion, Lack of accuracy & Service accuracy & \\
\hline Low efficacy, Worried about service & Service efficacy & \multirow{2}{*}{ Service anxiety } \\
\hline Rally point system, $1.15 \mathrm{~m}$ fixed height system & Competition rules & \\
\hline Defeat due to service mistakes, Olympic experience & Imprinting mistakes & \multirow{2}{*}{$\begin{array}{l}\text { Imprinting of } \\
\text { experiences }\end{array}$} \\
\hline Memory of yips symptoms & Memory of the feeling of yips & \\
\hline Game, Training perceived as a game & Game situation & \multirow{2}{*}{$\begin{array}{c}\text { Importance of } \\
\text { competition }\end{array}$} \\
\hline A match with a good opponent, A tense situation & Critical situation & \\
\hline Others' gaze and expectation, Pressure to win & Victory burden & \multirow{2}{*}{$\begin{array}{c}\text { Pressure of } \\
\text { achievement }\end{array}$} \\
\hline The desire to win and score & Desire to win & \\
\hline Service practice, Realistic practice & Service practice & \multirow{2}{*}{ Service practice } \\
\hline Action improvement & Action improvement & \\
\hline Positive self-talk & Self-talk & \multirow{2}{*}{ Psychological regulation } \\
\hline Service routine & Service routine & \\
\hline Changed to long/short, Forehand/backhand service & Service change & \multirow[b]{2}{*}{ Tactical coping } \\
\hline $\begin{array}{l}\text { Scoring in partner service, Playing with short service, } \\
\text { Strengthening defends }\end{array}$ & Change in game operation & \\
\hline Partner encourage, Partner considerations, Partner help & Partner role & \multirow{2}{*}{ Support from partner } \\
\hline Boundary of result, Increased in role, Shame transference & Partner burden & \\
\hline Leader’s encouragement, Helped in service training & Leader’s guidance & \multirow{2}{*}{ Leader’s coaching } \\
\hline Point out the wrong behavior, Leader's pressure & Leader's reprehension & \\
\hline Do not feel sympathy for colleague, Same experienced player & experience space & \multirow{2}{*}{ Advice of experienced } \\
\hline Advice on how to overcome yips & Advice on how to overcome yips & \\
\hline Yips symptom adaptation & Yips adaptation & \multirow{2}{*}{ Overcoming yips } \\
\hline Yips symptom recovery & Yips recovery & \\
\hline Yips symptom sustenance & Yips sustenance & \multirow{2}{*}{$\begin{array}{l}\text { Persistent } \\
\text { yips }\end{array}$} \\
\hline Yips symptom deepen & Yips deepen & \\
\hline
\end{tabular}


연구방법이다(Creswell, 2010). 근거이론방법은 어떠한 현 상이나 사건에 대하여 과정에 대한 설명 또는 특정 현상을 연구하기 위한 방법으로 기존의 이론 및 이론적 개념 틀을 기반으로 연구문제 및 가설검증하기 보다는 이론을 구축하 고자 활용되고 있다(Ryu, Jeong, Kim, \& Kim, 2012).

전사한 심층면담 자료는 개방코딩, 축코딩, 선택코딩 과 정을 거쳐 분석하였다. 먼저 개방코딩 과정에서는 문서화한 면담자료를 토대로 줄단위 분석을 통해 개념을 도출하고 개 념의 유사점과 차이점을 파악하여 하위범주와 상위범주로 범주화하였다. 축코딩에서는 개방코딩에서 도출된 범주들 의 속성과 차원을 파악하여 범주들을 연결함으로써 패러다 임 모형을 구성하였다. 선택코딩에서는 모든 범주들의 관계 를 설명하는 핵심범주를 도출하고 다른 범주들과 연결해 이 야기 윤곽을 전개하였다.

연구결과의 진실성을 확보하기 위하여 구성원 검토, 원 자료 재검토, 공동연구자 및 자문위원의 의견 수렴, 현장 관 찰, 선행연구 고찰 등을 활용하였다. 이러한 노력은 자료분 석 및 결과 도출 과정에서 발생할 수 있는 연구자의 주관적 해석을 최소화하고 결과 해석의 중립성을 지키는데 기여하 였다. 또한 연구 전반에서 일관성을 유지하고 연구결과의 현장 적용성을 증가시키는데 도움이 되었다.

\section{연구결과}

근거이론방법을 활용하여 배드민턴 선수의 서비스 입스 경험을 탐색한 결과는 다음과 같다.

\section{배드민턴 서비스 입스 영향 요인 범주화}

배드민턴 서비스 입스 영향 요인 탐색을 위한 개방코딩 결과, 〈Table 2〉와 같이 59개 개념, 31개 하위범주, 서비스 입스, 서비스 실수, 서비스 숙련도, 서비스 불안, 과거 경험 각인, 경기의 민감성, 성취 압박감, 서비스 연습, 심리 조절, 전술적 대처, 파트너지지, 지도자 코칭, 경험자 조언, 입스 극복, 입스 지속 등 15 개 범주가 도출되었다.

\section{배드민턴 서비스 입스 영향 요인 구조화}

배드민턴 서비스 입스 영향 요인을 구조화하기 위한 축코
딩 결과, 〈Fig 1〉의 패러다임 모형으로 구성되며 구체적인 내용은 다음과 같다.

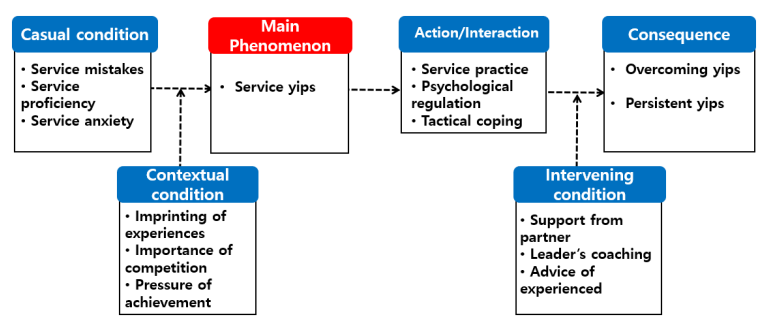

Fig 1. Badminton service yips paradigm model

\section{중심 현상}

연구 주제이자 초점이 되는 중심 현상은 서비스 입스로 나타났다. 서비스 입스는 배드민턴 선수가 경기 중 서비스 를 수행할 때 경험하는 심리적 문제로 생리적 증상과 심리적 증상, 통제력 상실의 하위범주가 도출되었다. 서비스 입스 를 겪는 배드민턴 선수는 서비스 수행 시 손 떨림, 몸과 팔의 경직, 심박수 증가, 잡아당기는 느낌 등과 같은 생리적 증상 과 당혹감, 창피함, 긴장 및 불안, 실수 걱정, 서비스 공포감 등의 심리적 증상을 경험하고, 그로 인해 서비스 동작에 오 류가 발생하여 심각한 실수를 범하게 된다.

"포핸드서비스 자세를 잡고 서비스 넣으려고 스윙을 하는데 뒤 에서 팔을 잡아당기는 느낌이 들면서 팔이 앞으로 안 오는 거예요. 그래서 ‘이게 뭐지?' 그랬는데... 00선수랑 경기할 때는 뒤에서 잡 아당기는 느낌이 아니라 임팩트 때 팔이 홱 돌아가는 거예요. 그런 증세가 심해지니까 서비스 할 때마다 팔이 갑자기 굳어지고 나중에 는 서비스가 안 되는 거예요(A선수)."

“득점하면 상대가공을 넘겨주잖아요. 그럼 그 공을 잡는 순간부 터 떨렸어요. '네트에서 뜨면 어떡하지, 미스하면 어떡하지' 이런 생 각이 제일 컸던 것 같아요. 계속 긴장되고 불안하더라고요(C선수)."

"처음에는 네트에 조금 뜨거나 아웃 냈는데 나중에 심할 때는 셔 틀콕이 네트 하단부에 맞거나 라켓 프레임도 만 맞고 떨어졌어요. 근 데 롱서비스도 잘 안 돼서... 롱서비스가 촥 날아가야 하는데 스피드 없이부웅 날아가는 거에요. 숏/롱서비스 다 불안했어요( $\mathrm{H}$ 파트너)."

이처럼 서비스 입스를 겪은 선수는 공통적으로 서비스 수 행 시 여러 생리적, 심리적 증상과 함께 스윙 동작에 문제가 생겨 일반적 수준 이상의 실수를 한다. 


\section{인과 조건}

인과 조건은 배드민턴 선수의 서비스 입스를 발생시키는 원인으로 서비스 실수와 서비스 숙련도, 서비스 불안이 도 출되었다. 중요한 경기에서의 서비스 실수와 반복된 실수는 이후 서비스 불안을 증가시켜 입스 발생과 지속, 심화의 주 요 원인이 되고 있다.

"예전에는 서비스 잘 넣었어. 근데 00언니랑 복식하면서 결승가 고 그러니까 긴장되잖아. 긴장될 때 몇 번 서비스 실수하고 나니까 그다음부터는 중요한 상황이 되면 또 실수할까봐 불안해지더라고. 복식에서는 서비스가 더 중요하잖아(D선수)."

서비스 입스 발생 이전부터 스윙(타구)에 문제가 있거나 셔틀콕 잡는 방법이 잘못된 경우, 서비스 동작의 일관성과 정확성이 부족한 경우에는 서비스 불안과 실수 확률을 증가 시켜 입스로 발전할 가능성이 있다.

"시합에서 서비스 실수하는 선수들 보면 어느 정도 예측이 돼. 왜나하면 연습 경기할 때 실수하거든. 물론 다 그런 건 아닌데, 00 조는 시합할 때 벤치코칭 들어가서 '실수하는 것 아니야' 마음속으 로 생각하면 여지없이 실수를 해. 그만큼 평소에도 정확성이 부족했 으니까 밖에서 봐도 아는 거지(N지도자)."

서비스 입스를 유발하는 가장 큰 원인은 서비스 수행 이 전부터 서비스 수행에 대해 갖는 과도한 긴장과 불안이다. 평소 서비스 수행에 낮은 효능감을 가진 선수는 정확하고 성 공적인 서비스 수행을 걱정한다. 랠리포인트제와 $1.15 \mathrm{~m}$ 높 이고정제의 규정 또한 선수로 하여금 더욱 정확한 서비스 수 행을 요구하므로 불안을 가중시킨다.

"서비스 넣으려고 준비할 때부터 긴장했던 것 같아요. 손이 떨리 는 증상은 100번 중에 2 3번 정도로 많지 않았는데 심리적인 긴장 을 많이 했죠. 이렇게 넣는 것이 맞는 건지, 서비스 넣으면 네트에 뜰 지, 네트에 걸릴지. 확신이 없다보니 불안감을 가지고 서비스를 했 던 것 같아요(E선수)."

이처럼 서비스 실수와 서비스 숙련도, 서비스 불안은 독립 적 혹은 복합적으로 서비스 입스 발생의 원인으로 작용한다.

\section{맥락 조건}

맥락 조건은 인과 조건이 서비스 입스로 연결되는 과정에
영향을 미치는 매개요인으로 과거 경험의 각인, 경기의 민 감성, 성취 압박감이 도출되었다. 중요한 대회에서 서비스 실수로 패배하거나 입스 증상으로 서비스 실수한 경험은 강 하게 각인되어 이후 서비스 수행에 영향을 미친다.

\section{"처음 서비스 입스가 왔을 때는 팔이 굳어지는 느낌이 아니라그 냥 갑자기 팔이 홱 돌아간 거예요. 누군가가 내 서비스를 방해한 것 처럼. 그래서 ‘뭐지?’ 웃어넘기고 그날 세 번 그러고 나니까 정신적 으로 딱 새겨지면서 다음 시합에 나갔는데 그 때는 팔이 굳어진 거 예요. 난 힘을 안주고 있는데 힘이 들어간 느낌(A선수)."}

서비스 입스 증상은 주로 연습보다 경기에서, 심한 경우 경기라고 지각한 훈련 상황에서도 유발된다. 또한 잘하는 상대와 경기하거나 듀스 같이 정확한 서비스를 요구하는 중 요한 상황에서 특히 심해진다.

"처음에는 연습할 때는 괜찮고시합 때만 그랬어요. 그러다가심 해지니까 연습할 때도 누가 앞에 서있으면 불안한 거예요. 근데 또 연습할 때 아무도 안 서있고 혼자 연습하면 괜찮았어요(C선수)."

더불어 타인에 의한 기대와 승리 압박감이 높고, 자기 스 스로 승리 욕심을 가진 경기에서는 불안과 실수 걱정 때문에 입스 증상이 유발되기도 한다.

"아무래도 마음속으로는 부담이 컸지. 00언니랑 하니까더 잘해 야 되잖아. 예전부터 서비스를 못 넣었던 것은 아니니까... 부담감이 생기니까 더 긴장되고 그래서 실수를 더 하게 된 것이 아닐까 생각 해(D선수)."

따라서 과거 경험 각인, 경기 민감성, 성취 압박감은 입스 증상을 유발, 심화시키는 매개요인으로 작용한다.

\section{작용/상호작용 전략}

작용/상호작용 전략은 중심현상을 조절, 관리하기 위한 개인적 시도를 의미하며, 서비스 입스를 완화시키거나 극복 하기 위한 전략으로 서비스 연습, 심리조절, 전술적 대처가 도출되었다. 먼저 선수는 잘못된 서비스 동작을 개선하고, 실제 경기와 유사한 상황을 연출하여 압박상황에서도 온전 한 서비스를 수행할 수 있도록 서비스 연습을 한다.

“왼쪽에서 서비스 넣으면 스윙이 돌아가서 바깥쪽으로 아웃이 
되는 거야. 그래서 자세를 잡을 때 발과 몸의 방향을 평소보다 왼쪽 으로 돌려서 넣었어. 그럼 스윙이 돌아가도 밖으로 아웃되지 않으니 까(F선수)."

더불어 서비스 입스에 수반되는 긴장과 불안, 공포감을 감소시켜 보다 편안한 심리상태로 조절하기 위하여 혼잣말 과 서비스루틴을 적용하기도 한다.

“롱서비스를 넣을까 말까 그 짧은 시간에 진짜 수 천 번을 고민 했어요. 딱 서비스 넣는 자리에 서서 '그래 롱서비스 넣자, 넣을 수 있어' 혼자 계속 주문을 넣고 자리에 섰다가다시풀고 그걸 세 번 정 도 한 것 같아요. 그리고 넣었는데 들어 간 거예요(A선수)."

입스를 겪는 와중에도 경기를 승리해야하기 때문에 선수 는 문제의 서비스를 포기하고 다른 종류로 변경하여, 수비 력을 강화하거나 경기운영 및 플레이 방식을 전환하는 전술 적 대처 방략을 강구한다.

"제가 엉덩이를 두 번 치면 롱서비스에요. 그러면 제가 빨리 수 비하려고 한 발짝 빠져 있는 거죠. 00 이는 롱서비스 넣고 사이드 쪽 만 수비하는 거에요. 제가 "내가 다 볼 테니까 너는 서비스 넣고 그 쪽만 봐라' 그렇게 미리 약속해요( $(H$ 파트너)."

이처럼 선수는 서비스 입스를 겪는 동안 심리조절과 더불 어 다양한 기술적, 전술적 방법을 동원하여 입스를 극복해 간다.

\section{중재 조건}

중재 조건은 서비스 입스 극복을 위한 선수 개인의 시도 과정에서 중재하는 외부 요인으로써 파트너 지지, 지도자 코 칭, 경험자 조언이 도출되었다. 복식 경기에서는 파트너가 해당 문제를 이해하고 격려해주는 한편, 성과 한계, 창피함 전이, 가중되는 역할 등과 같은 부담감을 경험하기도 한다.

“제가 “00아 우리 서비스 어떻게 할까?” 그러니까 “언니 죄송해 요. 제가 연습 할게요" 그러더라고요. 그래서 "그래 하면 돼. 내가 너 개인운동 할 때 같이 가서 해줄게." 그랬죠. 그렇게 같이 개인운 동 해주고, 서비스 연습하면 주변에 붙어서 이렇게 해보라고 이야기 하면서 도와줬어요(H파트너)."

지도자가 서비스 입스에 대해 공감하고 격려하며 연습을 도와줄 경우에는 서비스 불안 감소 및 극복 노력을 경주하는
데 반해, 잘못된 동작을 지적하거나 무관심, 또는 더욱 압박 할 경우에는 서비스 불안이 증가되어 입스 증상이 지속, 심 화된다.

“코치님이 올림픽 전에 거의 1 년 동안 매일 운동 전 30 분씩 서비 스 연습 도와주셨어요. 제 입장에서는 코치님이 조금 어렵잖아요. 어려운 사람이 리시버로 서있으니까 시합처럼 긴장되더라고요. 그 렇게 거의 1년 하니까 적응이 되어서 안 떨리는 것은 아닌데 그래도 서비스 실수를 덜 하게 되더라고요(B선수)."

더불어 동일 또는 다른 종목에서 입스 경험자의 공감과 극복 방법에 관한 조언은 입스 극복을 위한 노력의 촉매가 될 수 있다.

“농구선수인 친구한테 물어보니까 고등학교 때 갑자기 3점슛쏠 때 팔이 굳어서 못쏜 적이 있대요. 왜 그런지는 모르는데 한동안그 래서 계속 연습해서 연습량으로 극복했대요. 또 야구포수였던 친구 가 있는데 공을 받아서 다시 투수한테 던저줘야 하는데 송구가 안돼 서 운동 그만두었대요. 저만 그런 것이 아니어서 다행이라고 생각했 어요(A선수)."

이처럼 선수가 서비스 입스 극복을 위해 다양한 해결 방 안을 모색할 때 파트너, 지도자, 경험자의 도움은 입스 극복 의 가능성을 증가시킨다.

\section{결과}

다양한 원인과 매개요인이 결합하여 서비스 입스가 발생 하고, 이를 극복하기 위해 다양한 전략과 타인의 중재가 투 입된 결과는 서비스 입스 극복과 지속으로 나타났다. 서비 스 입스를 극복한 선수는 장기간 증상이 지속되면서 입스에 적응하거나 입스 발생 이전 상태로 완전히 회복한다.

"거의 1년간 포핸드롱서비스를 못 넣었어. 백핸드서비스로 경 기하면서 어느 날 보니까 괜찮아 진거야. 처음에는 서비스 연습도 하고 별 방법을 다 써도 안 되더니 그냥 1년 동안 시합할 때 포핸드 서비스 안 넣었더니 멀쩡해졌어. 그래서 나중에는 아무렇지도 않 게, 언제 그랬나는 듯이 포핸드서비스를 넣게 됐어(F선수)."

반면, 서비스 입스가 지속되는 선수는 증상의 경중에는 차이가 있으나 다양한 방법을 동원함에도 불구하고 장기간 동안 극복하지 못하거나 심화되어 경기와 연습상황에서 종 종 입스 증상을 경험한다. 
"아무도 없이 혼자 연습하는데도 서비스를 못했어요. 그러다가 조금 괜찮아 진 것 같아 넣어보려고 하면 선생님이나 누가 와서 서 있으면 또 안 들어가요. 점점 심해지니까 연습하는데도 누가 앞에 있으면 굳어서 못 넣었어요. 갈 때까지 갔죠(A선수)."

종합하면, 배드민턴 선수는 서비스 입스 발생 이후 장기 간 동안 점차 증상이 심해진 후 일부 선수는 완전히 회복하 는 반면, 일부선수는 적응하거나 지속한다.

한편, 과정분석을 통해 배드민턴 서비스 입스 경험을 시 간 흐름에 따라 단계화한 결과, 서비스 입스는 잠재단계, 발 생단계, 극복단계, 회복단계로 구성된다. 잠재 단계는 서비 스 입스 발생 이전 단계로 서비스 동작에 오류가 있고 실수 가 잦으며, 중요한 경기에서 서비스 실수로 패배하여 서비 스 입스로 전개될 위험성을 가지는 시기이다. 발생 단계는 선수 스스로가 문제를 인식하고 서비스 입스 증상이 유발되 어 심각한 서비스 실수를 하는 시기로 여러 매개 요인과 결 합되면서 생리적 - 심리적 증상과 함께 서비스 동작에 대한 통제력을 상실한다. 극복 단계는 발생된 서비스 입스를 완 화 또는 극복하기 위해 다양한 전략과 방법을 시도하는 시기 로 서비스 연습, 긍정적인 혼잣말, 루틴, 서비스 변경, 파트 너 및 지도자 격려, 경험자 조언 등을 활용하는 단계이다. 회 복 단계는 서비스 입스를 극복하기 위한 여러 가지 시도의 결과로 서비스 입스 발생 이전 상태로 완전히 회복되거나 입 스 증상에 적응, 여전히 지속되는 시기이다.

\section{배드민턴 서비스 입스 경험 체계화}

배드민턴 선수의 서비스 입스 경험을 체계화하기 위한 선 택코딩 결과, 본 연구의 핵심범주는 "배드민턴 서비스 입스" 로 도출되었다. 즉 배드민턴 서비스 입스는 배드민턴 선수 가 경기상황에서 서비스 기술을 수행할 때 손 떨림이나 몸과 팔의 경직, 과도한 긴장과 불안, 서비스 실수 걱정 등 생리 심리적 증상으로 스윙 동작에 오류가 발생해 의도한 서비스 동작을 하지 못하고 심각한 실수를 하는 만성적인 수행 장애 이다. 배드민턴 서비스 입스 경험에 관한 이야기는 다음과 같이 전개된다.

배드민턴 선수는 어느 날 갑자기 경기에서 서비스를 넣지 못한다. 지난 대회에 이유 없이 서비스가 아웃되거나 중요 한 순간 서비스 실수로 패배하면서 시작된 선수도, 혹은 언 제부터 서비스를 못 넣게 되었는지 기억나지 않은 선수도 있 다. 그냥 갑자기 서비스를 넣을 때 극도의 불안과 손 떨림으
로 스윙을 제대로 하지 못해 실수를 연발한다. 서비스에 문 제가 발생했다고 인식한 시점에는 이미 높은 불안과 공포가 유발되고 손이 떨리거나 팔이 경직되어 서비스를 제대로 넣 지 못한다. 이러한 생리 - 심리적 증상과 심각한 서비스 실 수를 여러 경기에 걸쳐 반복한 뒤에야 자신에게 심상치 않은 문제가 발생했음을 인지한다.

처음 서비스를 실수했을 때 선수는 '뭐지?' 당황스럽고 창피하다. 올림픽이나 결승 같이 중요한 경기에서의 서비스 실수는 창피함이 배가 되어 선수시절의 흑역사로 남는다. 평소 서비스 타구(스윙) 방식과 셔틀콕 잡는 방법이 잘못되 었던 선수와 정확성이 부족했던 선수는 서비스 수행에 대한 효능감이 낮고 실수 걱정을 많이 하기 때문에 더 빈번하게 실수한다. 또한 랠리포인트제는 서비스 실수와 부정확한 서 비스는 불리한 플레이로 이어지기 때문에 더욱 완벽한 서비 스 수행을 요구한다. 최근 적용된 $1.15 \mathrm{~m}$ 고정높이제 역시 자동화된 서비스 동작의 변화를 요구하기 때문에 서비스 불 안을 더욱 증가시킨다.

서비스를 넣기 위해 자리에 서서 자세를 잡으면 자꾸 지 난 경기에서 서비스가 네트 중간에 걸리고, 네트 위로 떠서 상대에게 푸싱 맞았던 기억이 떠오른다. 손이 떨리고 팔이 굳어져 스윙이 홱 돌아갔던 불쾌한 느낌이 반복될까봐 두렵 다. 가장 답답한 것은 훈련할 때는 괜찮은데 대회에 출전하 기만 하면 증상이 유발된다는 점이다. 잘하는 상대와 경기 할 때, 긴장되는 중요한 경기, 자기와 주변사람이 기대한 경 기에서는 더욱 증상이 심해진다. 아마도 경기의 민감성과 중요성이 높을수록, 또 성취 압박감이 높을수록 잘해야 한 다는 생각과 잘하고 싶은 마음이 크기 때문인 것 같다.

몇 개월째 서비스 입스가 지속된다. 이래서는 안 되겠다 생각한 선수는 나름대로 해결 방안을 고민한다. 먼저 서비 스 실수를 줄여보기 위해 파트너와 야간운동을 하거나 훈련 전 - 후 서비스 연습을 한다. 타구 스윙과 셔틀콕 잡는 방법 을 바꿔보고 실제 경기같이 긴장감을 느끼며 연습해본다. 또한 서비스 위치에서 심호흡하기 $\rightarrow$ 자세잡기 $\rightarrow$ 잘 넣을 수 있다 생각하기 $\rightarrow$ 스윙하기 등 자신만의 루틴을 만든다. 물론 자세를 잡았을 때 불안하거나 입스 증상이 느껴지면 자세를 풀었다가 다시 자세를 잡는 재루틴까지 계획한다.

더불어 선수는 입스 증상이 유발되더라도 경기에서 승리 할 수 있도록 또 다른 대안을 준비하는데, 포핸드롱서비스 가 안 되는 단식선수는 백핸드숏서비스로, 숏서비스가 안 되는 복식선수는 롱서비스로 변경하여 그에 맞게 경기운영 
방식도 변화시킨다. 이는 최악의 상황을 대비하여 익숙했던 서비스와 경기운영 방식을 포기하고 다른 서비스와 경기운 영 방식으로 입스 상황에 대한 대처방안을 마련한다.

선수는 제발 서비스를 잘 넣을 수 있게 해달라고 기도하 며 다음 대회에 출전한다. 코트 내 2분 워밍업 동안 서비스 에 더 신경을 쓴다. 경기 시작 직전, 마지막으로 서비스를 한 번 넣어보는데, 느낌이 괜찮다 싶으면 문제의 서비스를 넣 기로 결정하고, 입스 증상이 조금이라도 느껴지면 다른 서 비스를 넣기로 결정한다. 경기 중 서비스 넣을 차례가 되면 셔틀콕을 잡고 서비스 위치로 이동하면서 긴장과 불안을 감 소시키기 위해 “괜찮아, 잘 넣을 수 있어." 긍정적 혼잣말을 하고, 연습했던 서비스 루틴을 천천히 실행한다.

한편, 혼/복식경기에서는 서비스부터 공격적 플레이를 전개해야 득점 확률이 높아지므로 더욱 정확한 서비스가 요 구된다. 자신의 서비스 때문에 피해를 보는 파트너에게 미 안하다. 파트너는 "괜찮아. 내가 받아 줄테니 걱정하지 말고 편하게 넣어.”라고 격려해주며, 서비스 이후 플레이에 대한 수비를 강화한다. 가끔은 가중된 역할에 부담도 느끼고 서 비스 때문에 승리하지 못할 때는 속상하지만 티 내지 않고 함께 연습해준다.

선수와 파트너는 지도자와 해결 방안을 강구한다. 오랜 지도 경력을 가진 지도자는 유사한 선수를 종종 보았기 때문 에 선수의 어려움을 이해한다. 잘못된 서비스 동작 개선을 위해 지도하고, 때로는 자극을 주기 위해 질책하기도 한다. 하지만 선수는 지도자가 이해해주지 못하는 것 같아 속상하 고, 압박하는 모습이 야속하기도 하다. 그렇지만 결국 자신 의 문제라는 것과 스스로 극복해야 함을 잘 알고 있기 때문 에 지도자의 코칭에 감사하고 한편으로는 죄송하다.

서비스 입스를 겪는 선수에 대한 소문이 국내·외 배드민 턴계에 퍼져있다. 그래서 선수는 과거 서비스에 어려움을 겪었던 선후배를 찾아 조언을 구한다. 자신의 사례를 설명 하고 경험자의 사례를 들으며 자신의 경험을 이해하고 공감 해준다는 것에 위안을 얻는다. 우연히 다른 종목 친구에게 서비스 입스에 관한 이야기를 꺼냈는데, 다른 종목에서도 유사한 경험이 있다는 소식에 놀랍고도 반갑다. 선수는 '혼 자만의 문제는 아니구나, 많은 선수들이 겪는 흔한 일이구 나'라는 생각이 들어 안심한다.

시간이 많이 지난다. 그동안 여전히 경기에서 서비스 입 스 증상이 유발되고 나름대로 준비하고 계획했던 대안으로 견뎌냈다. 가까스로 승리한 경기도 있고, 여전히 서비스 때
문에 패배한 경기도 있다. 문제의 서비스를 포기하고 다른 서비스로 경기를 해온 선수는 어느새 완전히 회복되어 서비 스 입스를 극복했다. 또한 처음에는 두렵고 어쩔 줄 몰라 힘 들어했던 입스 증상이 오랜 기간 반복되다 보니 적응이 되어 비교적 쉬운 경기에서는 별 어려움 없이 평소처럼 서비스를 넣을 수 있다. 하지만 완전히 회복된 것은 아니어서 듀스나 결승 등 중요한 경기에서는 여전히 증상이 느껴진다. 서비 스에 신경 쓰느라 경기를 어떻게 했는지 기억하지 못할 정도 였던 과거에 비하면 이 정도도 감사할 따름이다.

\section{논의 및 제언}

배드민턴 선수의 서비스 입스 경험을 탐색한 본 연구결과 에 대한 논의는 다음과 같다. 먼저 개방코딩을 통해 배드민 턴 서비스 입스 영향 요인은 59개 개념, 31개 하위범주, 15 개 범주가 도출되었다. 배드민턴 서비스 입스 영향 요인은 골프 입스 영향 요인과 유사하다. 골프 선수의 입스 경험에 관한 연구(Choi et al., 2015; Dhungana \& Jankovic, 2013; Ko \& Huh, 2016; Sim \& Susl, 2016)에서는 과도 한 연습, 부상, 갑작스러운 체중 변화 등의 신체적 요인, 스 윙 교정과 변화, 슬럼프 같은 기술적 요인, 자신감 부족, 과 도한 압박과 불안, 과거에 대한 집착, 과거 최악수행, 트라우 마, 주변 인식 등의 심리적 요인, 경제적 부담과 갑작스러운 환경 변화 등의 환경적 요인을 입스 원인으로 보고하고 있 다. 특히, 과거 수행에 대한 집착이나 트라우마는 본 연구에 서 도출된 서비스 실수 각인과 동일한 맥락에서 입스 유발 및 심화의 주요 변인으로 간주할 수 있다.

더불어 배드민턴 선수의 입스 증상은 골프(Philippen \& Lobinger, 2012), 야구(Choi \& Chai, 2016), 크리켓 (Bawden \& Maynard, 2001), 여러 종목 선수(Bennett et al., 2015)의 입스 증상과 유사한 것으로 나타났다. 입스는 근육 경련 및 경직 등의 신체적 증상과 수행 공포, 자신감 결 여 등의 심리적 증상을 동시에 수반(Bennett et al., 2015; Stinear et al., 2006)하는데, 본 연구의 배드민턴 선수 역 시 유사한 형태의 신체적, 심리적 증상을 경험하였다. 뿐만 아니라 배드민턴 선수는 서비스 스윙 동작에서 손 떨림과 근 육 경직, 잡아당기는 느낌이나 팔이 회전되는 증상을 호소 하였는데, 이는 골프 선수의 클럽 페이스 각도가 틀어지거 나 혹은 의도하지 않았던 힘이 순간적으로 퍼터에 가해져 평 
소 쉽게 성공하던 짧은 거리 퍼팅을 실수하는 증상 (Blakeslee \& Blakslee, 2011; Smith et al., 2000, 2003)과 맥을 같이 한다.

둘째, 축코딩을 통한 배드민턴 서비스 입스의 패러다임 모형은 중심현상-서비스 입스, 인과조건-서비스 실수, 서비 스 숙련도, 서비스 불안, 매개 조건-과거 경험 각인, 경기의 민감성, 성취 압박감, 작용/상호작용 전략-서비스 연습, 심 리 조절, 전술적 대처, 중재 조건-파트너 지지, 지도자 코칭, 경험자 조언, 결과-서비스 입스 극복과 지속으로 구조화되 었다. 이러한 구조적 모형은 골프 선수 대상의 입스 연구 (Dhungana \& Jankovic, 2013; Kläampfl et al., 2013a, 2013b; Smith et al., 2000, 2003; Stinear et al., 2006) 를 종합한 결과와 같으며, 입스 발생 시 상태불안과 부정정 서가 높고, 심박수와 근전도가 증가하며 그립력과 클럽의 회전 범위 및 속도가 증가하는 공통된 특징은 중심현상인 배 드민턴 서비스 입스와 많은 부분 일치한다.

특히, 입스는 선수 개인이 주관적으로 지각하는 경기의 중요성과 민감성, 과도한 긴장감, 실패에 대한 걱정이 불안 을 가중시켜 수행 동작의 부조화 또는 동작수행의 오류를 발 생시켜 수행을 악화(Blakeslee \& Blakslee, 2011; Park, 2009; Philippen \& Lobinger, 2012; Rosted, 2005; Sim \& Susl, 2016)시키는데, 배드민턴 선수 역시 일반적인 경기상황보다 중요한 경기상황에서 입스 증상이 두드러지 게 나타났다. 또한 증상이 심화된 시기에는 경기라고 지각 하는 연습상황에서도 입스 증상을 경험하였는데, 입스 증상 이 연습상황에서는 나타나지 않는 반면, 실제 경기에서는 명확히 발생한다는 선행연구와 부분적으로 일치된다 (Blakeslee \& Blakslee, 2011).

입스를 경험한 선수는 심리기술훈련, 기술 분석 및 변화 시도, 휴식, 반복 훈련 등 다양한 극복 방법을 시도한다 (Back, 2017; Baik, 2019). 골프선수는 인지 재구성, 긍정 적 자기수용, 과거 회상기법, 심상, 자화, 목표설정, 루틴, 일 지작성 등과 같은 다양한 심리훈련이나 상담을 통해 입스를 극복(Ko \& Huh, 2016)하였는데, 높은 불안은 호흡곤란, 심박수 증가, 복통, 근육통, 손 떨림 등과 같은 신체적 증상 을 유발하므로 일차적으로 긴장과 불안, 부정정서 등의 심 리적 원인을 조절하는 것이 입스 증상 완화에 도움이 될 수 있다(Lee, 2006). 실제, 루틴훈련을 통해 치핑 입스를 극복 한 연구(Milne \& Morrison, 2015), 문제 중심 심상훈련을 통해 퍼팅 입스를 감소시킨 연구(Bell et al., 2009; Bell \&
Thompson, 2007)는 심리기술훈련이 입스 극복에 기여할 수 있음을 방증한다.

셋째, 선택코딩을 통한 본 연구의 핵심범주는 '배드민 턴 서비스 입스'로 도출되었다. 입스 연구에서는 입스의 발생 원인과 증상에 대한 신경 - 생리적 접근과 심리학 적 접근에는 다소 차이(Smith et al., 2003)가 있으나 근긴장증과 초킹이 상호작용할 때 심화된다는 점에는 비교적 공통된 입장이다(Adler et al., 2005; Bawden \& Maynard, 2001; Hill et al., 2010; Roberts et al., 2013; Smith et al., 2003). 또한 Bennett 등(2015)의 연구에서는 입스와 움직임 상실 증후군(lost move syndrome)이 갑작스럽고 일시적이며 미세한 운동 제 어 손실, 움직임 정지 등과 같은 유사한 특징이 나타남 을 발견하였다. 이는 배드민턴 선수의 서비스 수행에서 나타나는 증상이 초킹, 입스, 움직임 상실 증후군 등 여 러 현상과 유사함을 의미한다.

한편, 입스가 초보자보다 숙련자에게, 완벽주의 성향을 가진 선수들에게 발생률이 높고, 높은 압박과 불안, 스트레 스 상황에서 증상이 유발된다는 점(Roberts et al., 2013) 을 고려하면 일반적인 선수들에 비해 경기력 수준이 높은 국 가대표 선수들이 아시안게임이나 올림픽과 같은 메가스포 츠이벤트에서 입스를 경험할 가능성이 있다. 뿐만 아니라 입스는 일시적 혹은 간헐적으로 발생하거나 장기적으로 지 속되는가 하면 자연스럽게 극복되거나 재발(Kim \& Mun, 2009; Marquardt, 2009)할 수 있으므로 지속적인 관리와 지원이 이루어져야 할 것이다.

본 연구결과를 토대로 후속 연구 및 활용 방안에 대해 제 언하면 다음과 같다.

첫째, 배드민턴 서비스 입스 진단 기준 마련이 필요하다. 본 연구를 통해 입스 발생의 잠재성과 입스 증상의 경중 차 이를 확인하였다. 예컨대, 평소 서비스 수행에 대한 효능감 이 낮은 선수가 비교적 높은 심리적 압박감을 겪는 중요한 대회 및 경기에서 서비스 실수로 패배할 경우 그렇지 않은 선수에 비해 서비스 입스가 발생할 위험성이 높다. 또한 서 비스 입스 증상의 경중에 따라 심리적 개입 목표와 방법이 달라질 수 있어 서비스 입스 진단 기준이나 도구 개발에 관 한 후속연구가 필요하다.

둘째, 배드민턴 서비스 입스 시 나타나는 생리적, 심리적 증상과 운동수행력의 변화를 살펴볼 필요가 있다. 본 연구 의 참여자들이 보고한 손 떨림, 팔과 몸의 경직, 불안 등의 
증상과 스윙 동작의 오류를 객관적으로 확인할 수 있다면 배 드민턴 선수의 서비스 입스 경험을 보다 과학적으로 입증할 수 있을 것이다. 향후 서비스 입스를 겪는 배드민턴 선수를 위한 실제적인 극복 방안을 제공하기 위해서는 입스 증상에 대한 객관적 이해가 선행되어야 할 것이다.

마지막으로 서비스 입스 단계를 고려한 심리 지원이 필요 하다. 선수가 서비스 수행의 문제를 자각하는 시점은 이미 입스 증상이 심화된 경우가 많다. 또한 선수 개인별 입스 증 상과 지속 기간에 따라 증상에 대한 대처 방안이 달라질 수 있다. 예를 들어, 평소 서비스 효능감이 낮고 서비스 실수가 잦으며, 서비스 수행에 불안이 높은 선수는 조기 접근을 통 해 심리 지원을 한다면 입스 예방이 가능하다. 즉, 입스 증상 은 몇 달에서 몇 년까지 비교적 장기적으로 경험되는 만성 수행 장애이므로 잠재단계는 예방을 목적으로, 발생단계에 서는 증상 완화를 목적으로, 극복단계에서는 적응 및 회복 을 목적으로, 회복단계에서는 재발 방지를 목적으로 지원 방안을 모색해야 한다.

\section{참고문헌}

Adler, C. H., Crews, D., Hentz, J. G., Smith, A. M., \& Caviness, J. N. (2005). Abnormal co-contraction in yips-affected but not unaffected golfers: evidence for focal dystonia. Neurology, 64(10), 1813-1814.

Adler, P. (1981). Momentum: A theory of social action. Beverly Hills, CA: Sage.

Apitzsch, E. (2009). A case study of a collapsing handball team. Jern, S. \& Näslund, J.(Eds.). Dynamics Within and Outside the Lab. Proceedings from The 6h Nordic Conference on Group and Social Psychology, 35-52.

Back, M. R. (2017). The exploration and comparison of professional golfer's yips overcoming process. Master's Thesis. Yonsei University.

Baik, S. H. (2019). A study on the yips of baseball players. Master's Thesis. Seogang University.

Bawden, M., \& Maynard, I. (2001). Towards an understanding of the personal experience of the 'Yips' in cricketers. Journal of Sports Sciences, 19(12), 937-953.

Beilock, S. L., \& Gray, R. (2007). Why do athletes choke under pressure? In G. Tenenbaum \& R.C. Eklund (Eds.),
Handbook of sport psychology (3rd ed., pp. 425 - 444). Hoboken, NJ: Wiley.

Bell, R. J., \& Thompson, C. L. (2007). Solution-focused guided imagery for a golfer experiencing the yips: a case study. Athletic Insight: The Online Journal of Sport Psychology, 9(1), 52-66.

Bell, R. J., Skinner, C. H., \& Fisher, L. A. (2009). Decreasing putting yips in accomplished golfers via solution-focused guided imagery: A single-subject research design. Journal of Applied Sport Psychology, 21(1), 1-14.

Bennett, J., Hays, K., Lindsay, P., Olusoga, P., \& Maynard, I. W. (2015). Yips and lost move syndrome: Exploring psychological symptoms, similarities, and implications for treatment. International Journal of Sport Psychology, 46(1), 61-82.

Cho, M. J., Yook, D. W., Choi, J. S., \& Shin, J. T. (2015). The Study on Causes, Symptoms, and Coping Strategies of Driver Yips Phenomenon of Professional Golfers. Journal of Coaching Development, 17(2), 39-50.

Choi, K. Y., \& Chai, H. K. (2016). Study on the yips current states and coping method in high school baseball player through convergence. Journal of Digital Convergence, 14(11), 539-547.

Choi, M. R. (2011). The relationship of coach-athletic behavior fit, self-efficacy, sports performance and intrinsic motivation in badminton player. Korean Journal of Physical Education, 50(3), 301-311.

Choi, M. R., \& Kim, B. J. (2008). Athlete-coach behavior fit as a predictor of athletes' intrinsic motivation and self-efficacy. Korean Society of Sport Psychology, 19(2), 169-184.

Creswell, J. W. (2010). Qualitative inquiry \& research design: Choosing among five approaches. (Cho, H. S., Jeong, S. W., Kim, J. S., \& Kwon, J. S. Eds.). Seoul: Hakjisa.

Dhungana, S., \& Jankovic, J. (2013). Yips and other movement disorders in golfers. Movement Disorders, 28(5), 576-581.

Gu, H. M., Kim, Y. S., Sung, B. J., Kim, Y. J., Kim, H. K., Kim, M. S., Kang, K. J., \& Lee, J. S. (2012). Development and application of personal routines for badminton players prepare the 2012 London Olympics Games. Research report. Korea Institute of Sport Science.

Gu, H. M., Lee, S. M., Kim, Y. J., Kim, S. J., \& Han, D. W. 
(2009). Development and application of perceptual skill training for improving anticipation ability in national badminton player. Korean Journal of Sport Science, 20(1), 70-80.

Ha, T. K., Kim, H. G., Gu, H. M., \& Park, J. C. (2010). Applying and providing development direction through match analysis on badminton men's doubles matches for preparing 2008 Beijing Olympic Games. Korean Journal of Sport Science, 21(1), 947-955.

Han, S. J. (2017). Effects of the image training on the pro golfer's yips. Doctor's Thesis. Donga University.

Han, T. K, Kim, Y. N., \& Jung, S. H. (2014). Effect of competitive state anxiety and psychological skills in increase efficacy-building strategies program on athletes of badminton national women team and candidate women team. Journal of Coaching Development, 16(4), 25-34.

Hill, D. M., Hanton, S., Matthews, N., \& Fleming, S. (2010). Choking in sport: A review. International Review of Sport and Exercise Psychology, 3, 24 - 39.

Jang, D. S., \& Yun, G. U. (2003). The effects of psychological skills by goal orientations in badminton athletes. Korean Society of Sport Psychology, 14(3), 183-193.

Jeon, J. Y. (2014). Psychological momentum events in badminton competition. Korean Society of Sport Psychology, 25(4), 95-109.

Jeon, J. Y., \& Yun, Y. K. (2014). Maintenance process of psychological homeostasis in badminton competition. Korean Journal of Sport Science, 25(3), 575-589.

Jeon, J. Y., Yun, Y. K., Kim, Y. S., \& Park, S. H. (2019). Exploration on the psychological momentum strategy of national badminton players. Korean Journal of Sport Science, 30(4), 888-906.

Jung, E. H. (2007). The analysis regarding service and return in female badminton doubles. Master's Thesis. Busan University of Foreign Studies.

Kim, D. M. (2000). Effect of service in mixed doubles game of badminton. Master's Thesis. Wonkwang University.

Kim, H. K., \& Jung, S. H. (2014). Effect of badminton national team players applying PSTP effectiveness. The Korean Journal of Sport, 12(1), 7-17.

Kim, M. S., Gu, H. M., Kim, H. G., \& Kim, H. B. (2011). Identifying stressors and coping strategies of Korea national badminton women's doubles players. Korean Journal of Sport Science, 22(2), 1919-1938.

Kim, N. R., \& Mun, C. I. (2009). Performance disruption in sport: A case report and review of choking under pressure. The Korea Journal of Sports Science, 18(3), 567-587.

Kim, S. J., Gu, H. M., Park, S. H., \& Lee, S. M. (2007). Visual search strategies and reaction time differences between expert and intermediate badminton players. Korean Journal of Physical Education, 46(6), 179-190.

Kläampfl, M. K., Lobinger, B. H., \& Raab, M. (2013). Reinvestment-the cause of the yips?. Journal pone, 8(12), e82470.

Klämpfl, M. K., Lobinger, B. H., \& Raab, M. (2013). How to detect the yips in golf. Human Movement Science, 32(6), 1270-1287.

Ko, K. H., \& Huh, J. H. (2016). An in-depth study on the causes of yips among professional golfers and coping methods. Korean Society of Sport Psychology, 27(4), 63-74.

Lee, D. H., \& Huh, J. H. (2006). The relationship between the sport motivation and the performance strategy depending on the level of competitiveness among badminton players. Korean Society of Sport Psychology, 17(4), 203-214.

Lee, H. W. (2006). Neuropsychological factors affected on "Yips" phenomenon in amateur golfers. Korean Society of Sport Psychology. 17(4), 215-227.

Lee, J. H., \& Gu, H. M. (2003). Survey on thoughts of Korean women badminton players before and during single matches . Korean Journal of Sport Science, 14(2), 97-111.

Marquardt, C. (2009). The vicious circle involved in the development of the yips. International Journal of Sports Science, 4, Supplement 1: Annual Review of Golf Coaching, 678.

McDaniel, K. D., Cummings, J. L., \& Shain, S. (1989). The "Yips": a focal dystonia of golfers. Neurology, 39(2), 192-192.

Milne, D., \& Morrison, G. (2015). Cognitive behavioural intervention for the golf yips: A single-case design. Sport \& Exercise Psychology Review, 11(1), 20-33.

Noh, Y. W. (2012). Analyzing service and service return course of superior badminton men's singles players. Master's Thesis. Korea National Sports University.

Park, M. N. (2009). Exploration of 'Yips' phenomenon of 
professional golfers: A somatic approach. Master's Thesis. Myongji University

Philippen, P. B., \& Lobinger, B. H. (2012). Understanding the yips in golf: Thoughts, feelings, and focus of attention in yips-affected golfers. The Sport Psychologist, 26(3), 325-340.

Ra, K. M. (2002). Relationship between service and service return course of women's double game for badminton. Matser's Thesis. Korea National Sports University.

Roberts, R., Rotheram, M., Maynard, I., Thomas, O., \& Woodman, T. (2013). Perfectionism and the 'Yips': an initial investigation. The Sport Psychologist, 27(1), 53-61.

Rosted, P. (2005). Acupuncture for treatment of the yips?-A case report. Acupuncture in Medicine, 23(4), 188-189.

Ryu, K. U., Jeong, J. W., Kim, Y, S., \& Kim, H, B. (2012). Qualitative Research Methods. Seoul: Pakyoungsa.

Sachdev, P. (1992). Golfers' cramp: Clinical characteristics and evidence against it being an anxiety disorder. Movement Disorders, 7, 326 - 332.

Sim, J. I., \& Sul, J. D. (2016). An exploratory analysis on the causes of yips of professional golfers. The Korea Journal of Sports Science, 25(2), 129-142.

Smith, A. M., Adler, C. H., Crews, D., Wharen, R. E.,
Laskowski, E. R., Barnes, K., Bell, C. V., Pelz, D., Brennan, R. D., Smith, J., Sorenson, M C. \& Kaufman, K. R., (2003). The 'Yips' in golf. Sports Medicine, 33(1), 13-31.

Smith, A. M., Malo, S. A., Laskowski, E. R., Sabick, M., Cooney, W. P., Finnie, S. B., Crews, D. J., Eischen, J. J., Hay, I. D., Detling, N. J., \& Kaufman, K. (2000). A multidisciplinary study of the 'Yips' phenomenon in golf. Sports medicine, 30(6), 423-437.

Stinear, C. M., Coxon, J. P., Fleming, M. K., Lim, V. K., Prapavessis, H., \& Byblow, W. D. (2006). The yips in golf: multimodal evidence for two subtypes. Medicine and science in sports and exercise, 38(11), 1980-1989.

Strauss, A., \& Corbin, J. (2001). Stage of grounded theory. K. R. Shin.(Ed.). Seoul: Hyunmoonsa.

Sung, H. K., \& Gu, H. M. (1992). Anticipation of stroke course and the information sources in badminton single game. Korean Society of Sport Psychology, 3(2), 67-85.

Yoon, H. C., \& Lee, J. H. (2015). The relationship between the initial stroke selection and athletes' performance during the badminton men`s doubles matches . Korean Journal of Sport Science, 26(1), 174-188. 


\title{
배드민턴 선수의 서비스 입스 경험
}

\author{
전재연 ${ }^{1}$, 김현주 ${ }^{2}$, 김정수 ${ }^{3}$, 박상혁 ${ }^{1}$ \\ ${ }^{1}$ 한국스포츠정책과학원 선임연구원 \\ ${ }^{2}$ 한국체육대학교 강사 \\ ${ }^{3}$ 세명대학교 교수
}

[목적] 본 연구는 근거이론방법을 활용하여 배드민턴 선수의 서비스 입스 경험을 심층적으로 탐색하는데 목적이 있다. [방법] 서비스 입스를 경험한 배드민턴 선수와 그들의 복식 파트너 및 지도자 총 14 명을 대상으 로 심층면담을 진행해 자료를 수집하였다. 수집된 원자료는 근거이론방법을 활용해 전사 및 코딩, 패러다임 모형으로 분석하였다. [결과] 첫째, 개방코딩 결과, 배드민턴 서비스 입스에 관한 59개 개념, 31개 하위범주, 15 개의 상위범주가 도출되었다. 둘째, 축코딩 결과, 서비스 입스, 서비스 실수, 서비스 숙련도, 서비스 불안, 과거 경험 각인, 경기의 민감성, 성취 압박감, 서비스 연습, 심리 조절, 전술적 대처, 파트너지지, 지도자 코칭, 경험자 조언, 입스 극복, 입스 지속 등의 범주들이 패러다임 모형으로 구조화되었다. 셋째, 선택코딩 결과, 본 연구의 핵심범주는 ‘배드민턴 서비스 입스’로 도출되었다. 즉, “배드민턴 서비스 입스”는 배드민턴 선수들이 경기상황에서 서비스 기술을 수행할 때 손 떨림이나 몸과 팔의 경직, 과도한 긴장과 불안, 서비스 실수 걱정 등의 생리적, 심리적 증상으로 스윙 동작에 오류가 발생해 의도한 서비스 동작을 하지 못하고 심각한 실수를 하는 만성적인 수행 장애이다. [결론] 본 연구가 배드민턴 서비스 입스를 이해하고 설명할 수 있는 이론적 근 거가 되고, 서비스 입스로 인해 심리적 어려움을 배드민턴 선수에게 공감을 형성하여 효과적인 극복 방안을 강구하는데 유용한 자료가 되기를 기대한다.

주요어: 서비스 입스, 배드민턴 선수, 지도자 코칭, 입스 극복, 근거이론방법 